\title{
Author Correction: Comprehensive profiling of circular RNAs with nanopore sequencing and CIRI-long
}

Jinyang Zhang $\mathbb{D}$, Lingling Hou, Zhenqiang Zuo, Peifeng Ji, Xiaorong Zhang, Yuanchao Xue and Fangqing Zhao D

Correction to: Nature Biotechnology https://doi.org/10.1038/s41587-021-00842-6, published online 11 March 2021.

In the version of this article initially published online, an additional PCR step was missing at the beginning of the last paragraph in the "Nanopore library preparation" section of the Methods: To obtain sufficient cDNA products for sequencing, PCR amplification was performed using $2 \mu \mathrm{L}$ of cDNA with NEBNext LongAmp Taq DNA Polymerase and SMARTer primers under the following conditions: 95 ${ }^{\circ} \mathrm{C}$ for $30 \mathrm{~s} ; 19$ or 20 cycles of $95^{\circ} \mathrm{C}$ for $15 \mathrm{~s}, 62^{\circ} \mathrm{C}$ for $15 \mathrm{~s}$, and $65^{\circ} \mathrm{C}$ for $120 \mathrm{~s} ; 65^{\circ} \mathrm{C}$ for 6 min and hold at $4{ }^{\circ} \mathrm{C}$. Also, the following has been added at the end of this section: Steps for library construction are detailed in the CIRI-long manual pages at https://ciri-cookbook. readthedocs.io/en/latest/CIRI-long_sequencing.html. The error has been corrected in the print, PDF and HTML versions of the article.

Published online: 30 April 2021

https://doi.org/10.1038/s41587-021-00934-3

(๑) The Author(s), under exclusive licence to Springer Nature America, Inc. 2021

\section{Publisher Correction: Questions swirl around failures of disease-modifying Huntington's drugs}

Cormac Sheridan

Correction to: Nature Biotechnology https://doi.org/10.1038/s41587-021-00955-y, published online 10 June 2021.

In the version of this article initially published, an organization name was given as the Cure Huntington's Disease Initiative (CHDI) Foundation. The name has been changed to simply the CHDI Foundation. The error has been corrected in the PDF and HTML versions of the article.

Published online: 21 June 2021

https://doi.org/10.1038/s41587-021-00987-4

( ) The Author(s), under exclusive licence to Springer Nature America, Inc. 2021

\section{Publisher Correction: 'Super-antibodies' could curb COVID-19 and help avert future pandemics}

Elie Dolgin

Correction to: Nature Biotechnology https://doi.org/10.1038/s41587-021-00980-x, published online 22 June 2021.

In the version of this article initially published online, the name of the company Vir Biotechnology was given as Vir Therapeutics. The error has been corrected in the print, PDF and HTML versions of the article.

Published online: 29 June 2021

https://doi.org/10.1038/s41587-021-00997-2

(C) The Author(s), under exclusive licence to Springer Nature America, Inc. 2021 